\title{
Legacy of the Space Shuttle From an Aerodynamic and Aerothermodynamic Perspective
}

\author{
Fred W. Martin* \\ NASA Johnson Space Center, Houston, Texas, 77058
}

\begin{abstract}
The development of the Space Shuttle Orbiter thermal protection system heating environment is described from a design stand point that began in the early 1970s. The desire for a light weight, reusable "heat shield" required the development of new technology, relative to previous manned spacecraft, and a systems approach to the design of the vehicle, entry guidance, and thermal protection system. Several unanticipated issues had to be resolved in both the entry and ascent phases of flight, which are discussed at a high level. During the life of the Program, significant improvements in computing power and numerical methods have been applied to Space Shuttle aerodynamic and aerothermodynamic issues, with the Shuttle Program often being the motivation, and or sponsor of the analysis development.
\end{abstract}

\section{Nomenclature}

Symbols

$g, G$

$=$ Acceleration due to gravity

Acronyms

BLT

CFD

DAC

DFI

DPLR

DSMC

DTO

KSC

$L / D$

LAURA

OFT

OV

$=$ Boundary-Layer Transition

$=$ Computational Fluid Dynamics

$=$ DSMC Analysis Code

$=$ Development Flight Instrumentation

$=$ Data-Parallel Line Relaxation CFD code

$=$ Direct Simulation Monte Carlo analysis method

$=$ Detail Test Objective

$=$ Kennedy Space Center

$=$ Lift to Drag ratio

= Langley Aerothermodynamic Upwind Relaxation CFD code

$=$ Orbiter Flight Test

OVERFLOW $=$ Overset grid Flow solver CFD code

RCG $\quad=$ Reaction Cured Glass tile coating

STS $\quad=$ Space Transportation System

SSLV $\quad=$ Space Shuttle Launch Vehicle

TPS $\quad=$ Thermal Protection System

$\mathrm{X} / \mathrm{L} \quad=$ Non-dimensional Length

\section{Introduction}

T ooking back over the last 40 years of Space Shuttle development and operations, the legacy from an Laerodynamic/aerothermodynamic perspective is the development of the first reusable Thermal Protection System (TPS) for a manned spacecraft, combined with the dramatic improvement in the state-of-the-art in aerodynamic and aerothermodynamic capability that has been used to support the Shuttle Program. Across the country; government, industry, and academic personnel have been inspired to push the boundaries of what can be accomplished both computationally and with ground based test facilities. The complex physics of hypersonic,

\footnotetext{
${ }^{*}$ Applied Aeroscience and CFD Branch, AIAA senior member.
} 
chemically reacting flows, rarefied non-continuum flows, and the aerodynamic complexity of the Space Shuttle Launch Vehicle (SSLV) design have all yielded to advances in computing power and to improvements in numerical methods. Today's supercomputers are 9 to 10 orders-of-magnitude faster than the computers of the 1970s. As the computers improved, so has the software that models aerodynamic flows. The following brief summary illustrates the capability that has been developed to address Space Shuttle related issues since STS-1.

\section{The First Reusable Thermal Protection System}

The development of the Orbiter's Thermal Protection System (TPS) is a fascinating story of systems design that is not well known outside of a few key individuals who were involved in the Space Shuttle Program from the 1960s through the development and early flights of the Space Shuttle. ${ }^{1}$ The Systems Engineering lessons that they learned from the Mercury, Gemini, and Apollo Programs were used in the design of the Space Shuttle TPS in order to develop a light weight, reusable, system that could protect a conventional aluminum airframe. New technology had to be developed for the TPS, along with the avionics systems (two fault tolerant, digital fly-by-wire), and the propulsion systems in contrast to all other subsystems, where existing technology was to be used. The following discussion is intended to be presented at a high level, while the technical details can be found in the references.

\section{A. Apollo Heat Shield Experience}

Manned spacecraft use a high drag, blunt body design ${ }^{2}$ to dissipate the tremendous kinetic and potential energy that was imparted by the launch vehicle. As the vehicle enters the atmosphere, a strong shockwave forms in front of it, compressing and heating the air dramatically, thus the energy of the vehicle is transferred to the atmosphere while the vehicle slows down due to the aerodynamic drag caused by the high pressure in front of it, and low pressure behind it. The role of the heat shield/TPS is to protect the vehicle from the high temperature gas and minimize the amount of heat that is absorbed during entry. The heat shield material characteristics, vehicle lift to drag ratio (L/D), and entry trajectory are all interrelated. The blunt body design of the Apollo capsules yielded a large drag force combined with a small amount of lift which was used to control the trajectory.

For Apollo, the heat shield had to be designed before the lunar trajectories were known, thus two extreme trajectories were used to bound the heat rate and heat load. Heat rate was maximized with a 20g emergency lunar return trajectory while heat load was maximized by a shallow entry trajectory that just barely captured the space craft in the atmosphere (a shallower trajectory would pass through the atmosphere and back into space). ${ }^{3}$ Large uncertainties in the lunar return trajectory, heat shield material properties, and the aerothermodynamic heating environment, resulted in a compounding of the conservatism in each aspect of the design, which is discussed in Reference [1]. As a result, the heat shield thickness was overdesigned by a factor of two for the lunar return missions, with the exception of the windward torus corner, which is shown in Figure 1. The high velocity local flow expanding around the corner produced more recession, in this area, than was expected based on stagnation flow arc jet test of the material, and the inner structure reached its design temperature limit of 589K (600F) during flight.

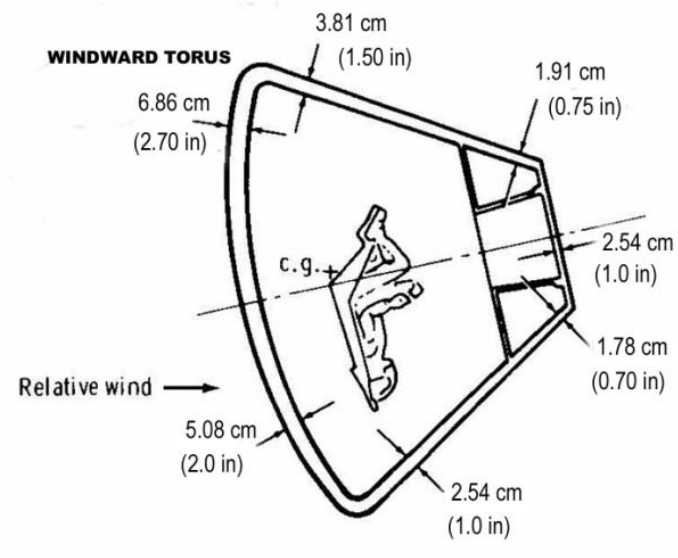

Figure 1. Apollo Command Module heat shield thickness. 


\section{B. Space Shuttle TPS Design Requirements}

The reusable nature of the Space Shuttle design dictated that the TPS system be an efficient, reusable, minimum weight system. This was accomplished by designing the vehicle and the entry flight profile to maintain laminar flow during the peak heating portion of the trajectory. The vehicle windward surface geometry and roughness were optimized to minimize disturbances in the flow field between the bow shock and surface as shown in Figure 2.

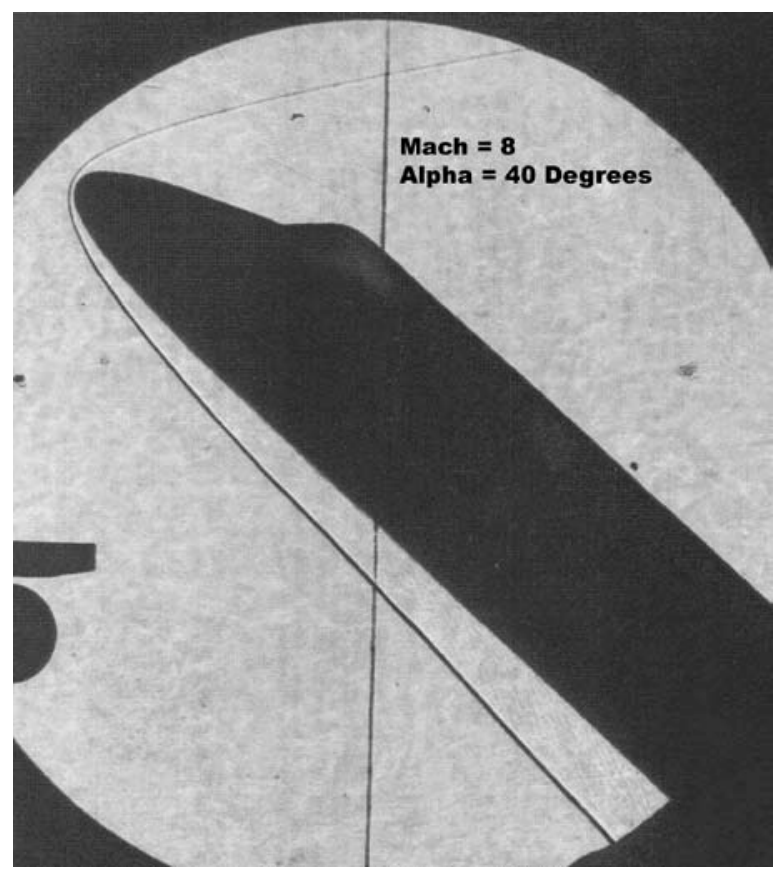

Figure 2. Space Shuttle Orbiter Shock Layer at Mach = 8, Angle-of-Attack $=40$ Degrees.

Conservatism in the design was minimized by using a nominal trajectory (without dispersions), nominal material properties, nominal heating methods and an aerodynamic smooth surface. ${ }^{4}$ A polar orbit, high cross range (2778 $\mathrm{km}$, or 1500 nautical miles) mission from the Western Test Range was used as the design trajectory since this is more severe than operational flights from the Kennedy Space Center (KSC). The approach was to design for the Western Test Range mission, then fly the Orbiter Flight Test Program (OFT) missions (first 4 missions) from KSC with a minimum cross range entry trajectory for the first flight. During the OFT flights, the severity of the entry conditions would be increased, with the anticipation that the flight data would demonstrate enough margin to fly the operational missions. A comparison of the Apollo and Orbiter Altitude vs. Velocity entry profiles is shown in Figure 3.

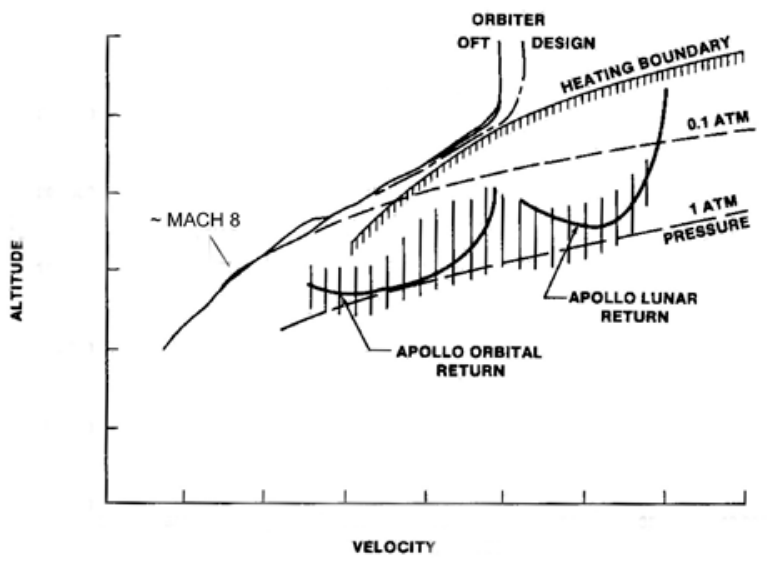

Figure 3. Altitude vs. Velocity for the Space Shuttle Orbiter compared with Apollo. 
The Orbiter's entry trajectory was designed to stay higher in the atmosphere, relative to Apollo, which allowed the vehicle to experience laminar heating rates until approximately Mach 8 thus reducing the maximum temperature the reusable TPS materials would be exposed to and the heat load which drove the insulation (thickness and weight) requirements. Also, the design community actively worked to minimize the uncertainty and "compound conservatism" that had occurred during the Apollo Program. Their success at reducing the difference between the design and actual requirements, which was the largest component of the uncertainty in the Apollo Program, can be seen in Figure 4. The difference between the STS-1 and the Orbiter design trajectory is within the uncertainty of the preflight entry environment and the TPS performance, in contrast to the Apollo experience.

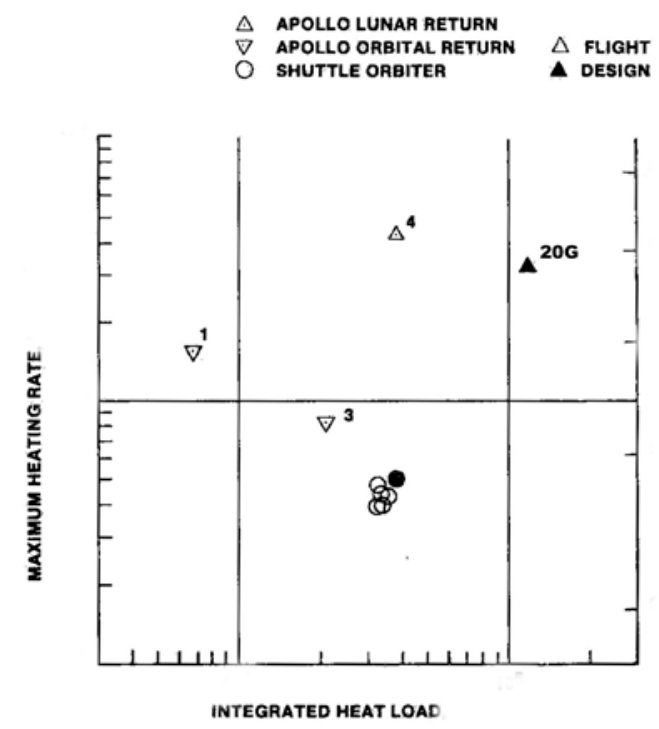

Figure 4. Comparison of entry design vs. flight conditions for Apollo and the Space Shuttle OFT flights.

\section{Space Shuttle Aerothermodynamic Design Approach - Three levels of Sophistication}

\section{Simplified Heating Model}

The three different levels of sophistication that were used to predict the aerothermodynamic heating environment to the TPS are described in Reference 5. The initial level used wind tunnel heat transfer data referenced to the stagnation heating of a 1 foot sphere. This data was scaled to flight conditions based on stagnation heating to the reference sphere, assuming equilibrium air thermodynamic conditions in the shock layer. Boundary-layer transition and turbulent heating data was scaled from wind tunnel to flight based on the Reynolds Number behind a normal shock. This approach was used to derive the entry trajectory that maintained laminar heating as shown in Figure 3.

\section{Design Methodology}

The second level of sophistication was the primary approach for predicting the surface heat transfer. Equilibrium air, boundary-layer code predictions for simplified 2-D flow field models (sphere, cone, wedges, and swept cylinders) were corrected for 3-D effects with wind tunnel data at Mach 8 from a smooth surface Orbiter wind tunnel model as shown in Figure 5. 


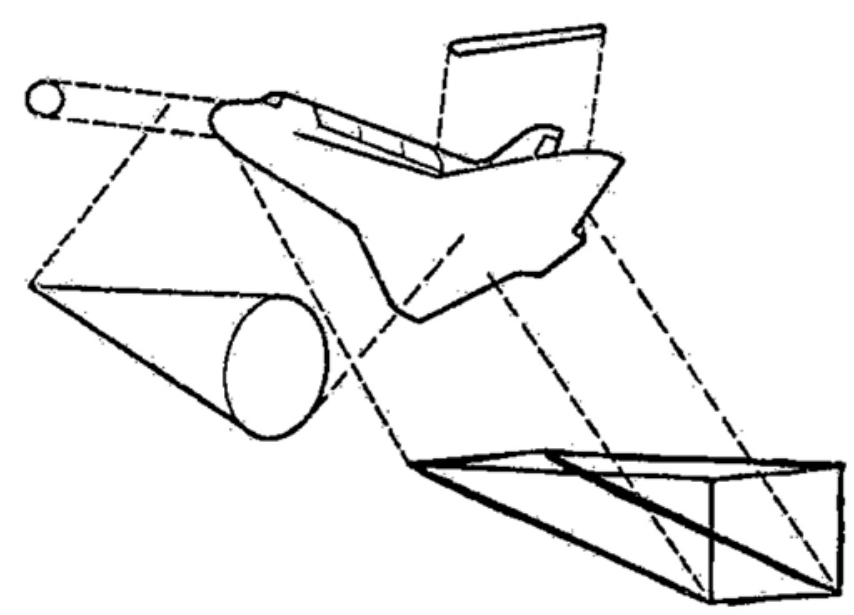

Figure 5. Representative flow field models, (sphere, cones, wedges, and swept cylinders) were used to scale wind tunnel data from an Orbiter model.

Figure 6 illustrates how the ratio of predicted heat transfer to measured heat transfer, at wind tunnel conditions (the calibration factor in Figure 6) was applied to the 2-D model predictions at flight conditions to arrive at the pre-flight heat transfer values for design of the TPS system. Boundary-layer transition predictions, at flight conditions, were correlated with wind tunnel data using momentum-thickness Reynolds number divided by the local Mach number ${ }^{6}$, which required the calculation of the boundary layer parameters with numerical methods. The results were similar to those obtained with the simplified approach, which was described in the "Simplified Heating Model" section.

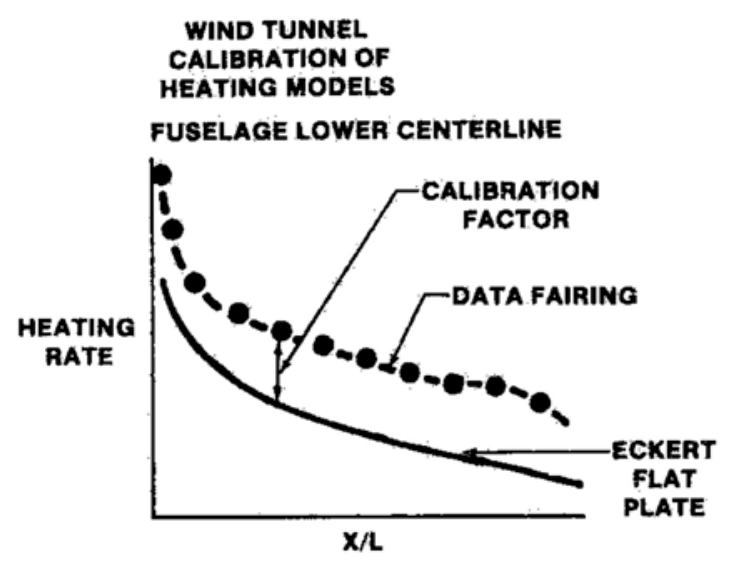

Figure 6. Illustration of how the ratio of wind tunnel data to simplified model heating rates was obtained. The ratio of the wind tunnel data to the model flow value was used to calculate the calibration data thus correcting the simplified model for the Orbiter's three dimensional geometry.

\section{Three Dimensional Flow Field Approach}

In order to provide additional confidence in the entry heating environment, a series of benchmark three dimensional calculations were performed prior to the first flight. The computer technology in the late 1970s and early 1980s restricted this approach to 3-D inviscid flow fields while a 2-D boundary layer code was used to predict the surface heat transfer. ${ }^{7,8}$ This approach was limited to supersonic flow downstream of the subsonic nose region, but did provide confidence in the design approach before the flight of STS-1, as discussed in Reference 3. 


\section{Boundary-Layer Transition}

Even though the Orbiter shape had been designed to minimize flow field disturbances in the shock layer that could cause boundary-layer transition, Rockwell International, (the prime contractor) used a conservative approach in their wind tunnel test program. They reasoned that a rough tile installation would behave like individual roughness elements and could be modeled in the wind tunnel with spherical protuberances. In addition, the noise in a wind tunnel tends to cause early boundary-layer transition, relative to flight, which is also conservative. Thus for design, a "nominal" set of data was used from what turned out to be a conservative approach.

\section{E. Surface Roughness}

The original tile installation requirement (1974), from a surface roughness standpoint, specified that tile to tile steps had to be less than a millimeter in order to remain "aerodynamically" smooth. ${ }^{9}$ When it became obvious that construction of Columbia (OV-102) could not meet this requirement in a cost effective and timely manner, a wind tunnel test program was conducted with a 0.0175 scale model at Mach 8. The model, which had been previously tested in its smooth condition, was modified by plating raised tiles randomly over $25 \%$ of the surface. ${ }^{10}$ Using this data, the tile installation criteria were relaxed by roughly a factor of 4 , while the as built roughness distribution for STS-1, came in between the two criteria. ${ }^{11}$ Also, prior to the first flight, no one considered the possibility that gap fillers, installed between the tiles, might come loose and protrude enough to make very effective boundary-layer trips. Nor did they anticipate the amount of tile damage, from launch debris, that would occur. Fortunately, boundary-layer transition is not as sensitive to the cavity type of damage as compared to protruding gap fillers, which occurred less frequently than the tile cavity type of debris damage.

\section{F. Surface Catalysis}

The flow field conditions behind the bow shock are hot enough to dissociate the oxygen and nitrogen molecules into atoms and ionize them. Metallic TPS surfaces will act as a catalyst, causing the atoms to give up energy as they recombine, thus adding additional heating to the surface. In contrast, the Reaction Cured Glass (RCG) coating on the tiles, have a minimal catalytic effect. However, for design purposes, the TPS was assumed to be fully catalytic. Special catalytic coatings were flown on select tiles during the OFT program to evaluate the difference between the coated tiles, which were strongly catalytic, and the nominal tiles which were shown to be weakly catalytic. $^{12,13,14,15,16}$

\section{G. STS-1 Pre-Flight Assessment}

In order to minimize risk during the first flight, a benign entry trajectory with minimum cross range was planned and the entry heating predictions included trajectory dispersions, heating uncertainties, and the effects of the as-built surface roughness. The resulting uncertainties were combined in a root-sum-square approach and provided additional confirmation that sufficient margin existed in the TPS design for the flight, as described in Reference 5.

\section{H. STS-1 Flight Experience}

The Orbiter windward surface had 96 surface temperature measurements installed in the tiles so the RCG coating temperature could be recorded, and thus the surface heat transfer could be calculated. Unfortunately, the Development Flight Instrumentation (DFI) tape recorder failed during the mission and was not able to record the entry data. However, the telemetry system regained contact, after the radio black out period ended, thus data was down linked starting at 1050 seconds after Entry Interface (122 km, or 400,000 ft). A comparison of the heat rate predictions and the flight measured heat rate at $\mathrm{X} / \mathrm{L}=0.4$ on the vehicle centerline is shown in Figure 7 . The flight data starts at 1050 seconds and is the "jagged" looking solid line. The laminar flow heat rate is decreasing until 1140 seconds at which time the boundary layer began to transition to turbulent flow at this location due to damage that had occurred on the nose gear door during ascent. The flow is fully turbulent by 1200 seconds and then the heat rate decreases as the trajectory becomes less severe. The solid line, labeled "nominal transition" is the heat rate profile that was used to design the TPS at this location, while the dashed line is the STS-1 pre-flight assessment which included the uncertainties. The 3 sigma uncertainty on boundary layer transition indicated that transition would occur at 830 seconds into the entry (Mach 20.5), while the nominal transition time of 1040 seconds (Mach 14) is shown with a solid line. The dashed line is the heating rate predictions that were calibrated with the three dimensional flow field (CFD) results. The effect of the tile catalysis, or lack off, can also be seen. The top of the symbol would be fully catalytic, while the bottom is non-catalytic. 


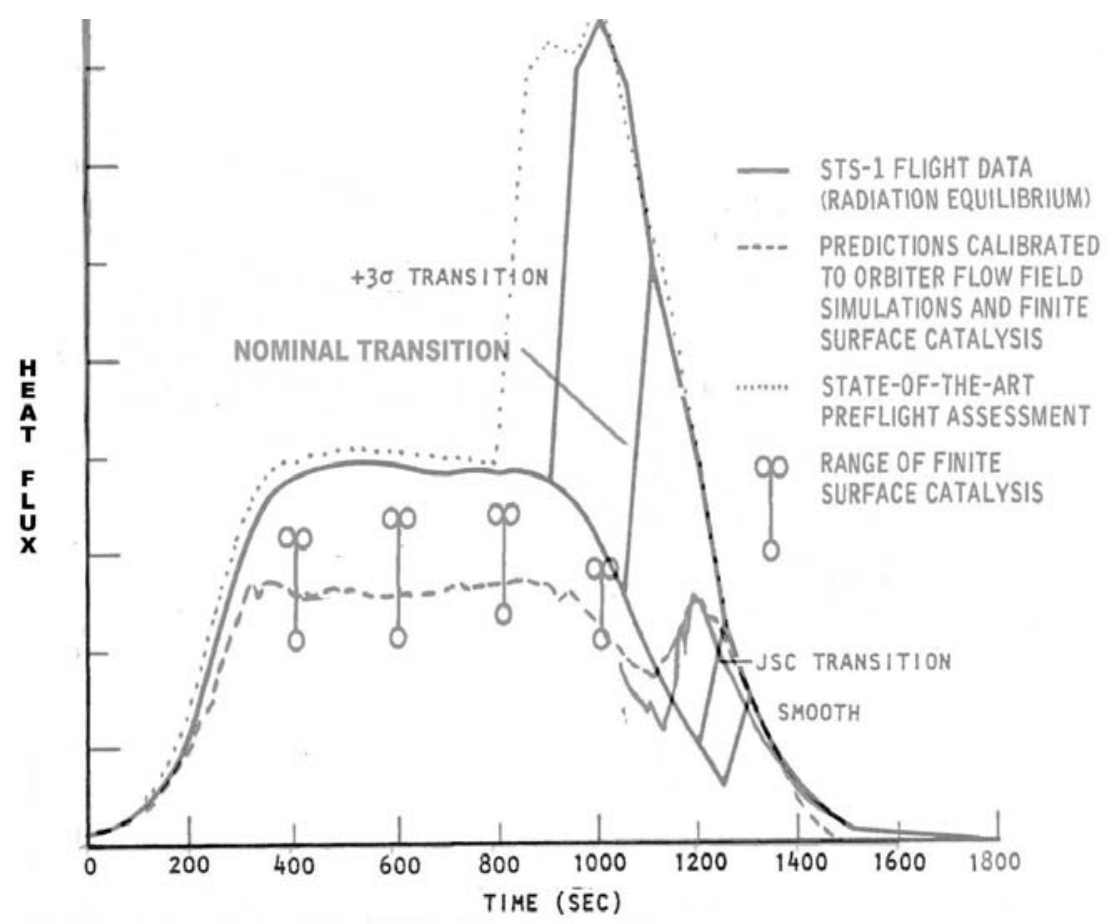

Figure 7. Heat rate predictions compared to STS- 1 flight data at $\mathrm{X} / \mathrm{L}=0.4$ on the vehicle centerline.

\section{STS-1 Boundary-Layer Transition - Flight Experience}

Following the loss of Columbia and her crew during the STS-107 mission, analysis tools were developed to predict entry heating to a damaged TPS. As part of the tool development, the NASA and Boeing team compiled an excellent summary of TPS damage induced boundary-layer transition data. ${ }^{17}$ Eleven shuttle missions, that experienced early boundary-layer transition due to protruding gap fillers or cavities in the tile, are documented and compared to the revised method for predicting boundary-layer transition. STS-1 had a significant gouge and related protruding gap filler on the nose gear door as shown in Figure 8, which caused early boundary-layer transition on the starboard side of the vehicle. Additional photographs, (not shown) indicate that the gap filler was exposed in the cavity, and probably inclined above the original surface during entry. If so, the gap filler would have contributed to the flow disturbances that cause early boundary-layer transition.

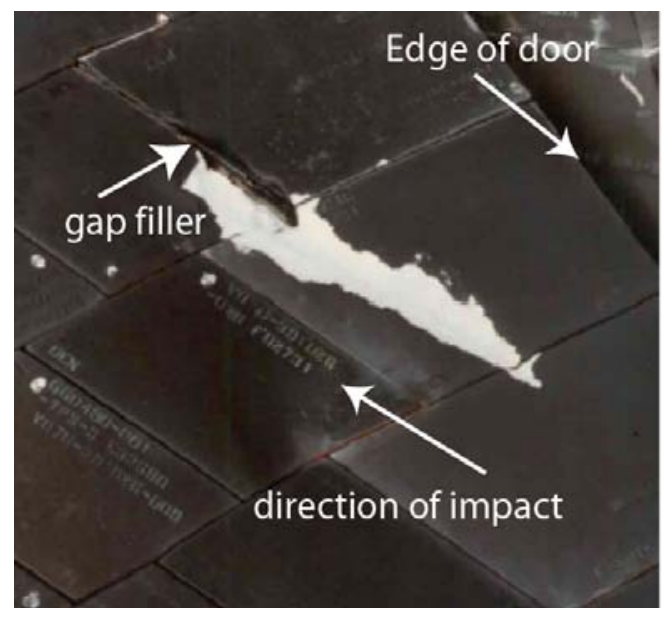


Figure 8. TPS tile and gap filler damage during STS-1 on the Nose Landing Gear Door. The gouge was approximately $25 \mathrm{~cm}$ long, by $2 \mathrm{~cm}$ wide by $2.5 \mathrm{~cm}$ deep.

Figure 9, which is from Reference 13, illustrates the extent of turbulent flow based on the TPS damage assessment methods developed for the support of STS-114 and following missions. This figure compares the transition time, based on the flight data from STS-1, with the assessment tool prediction and turbulent boundary-layer spreading from the team's Wedge tool.

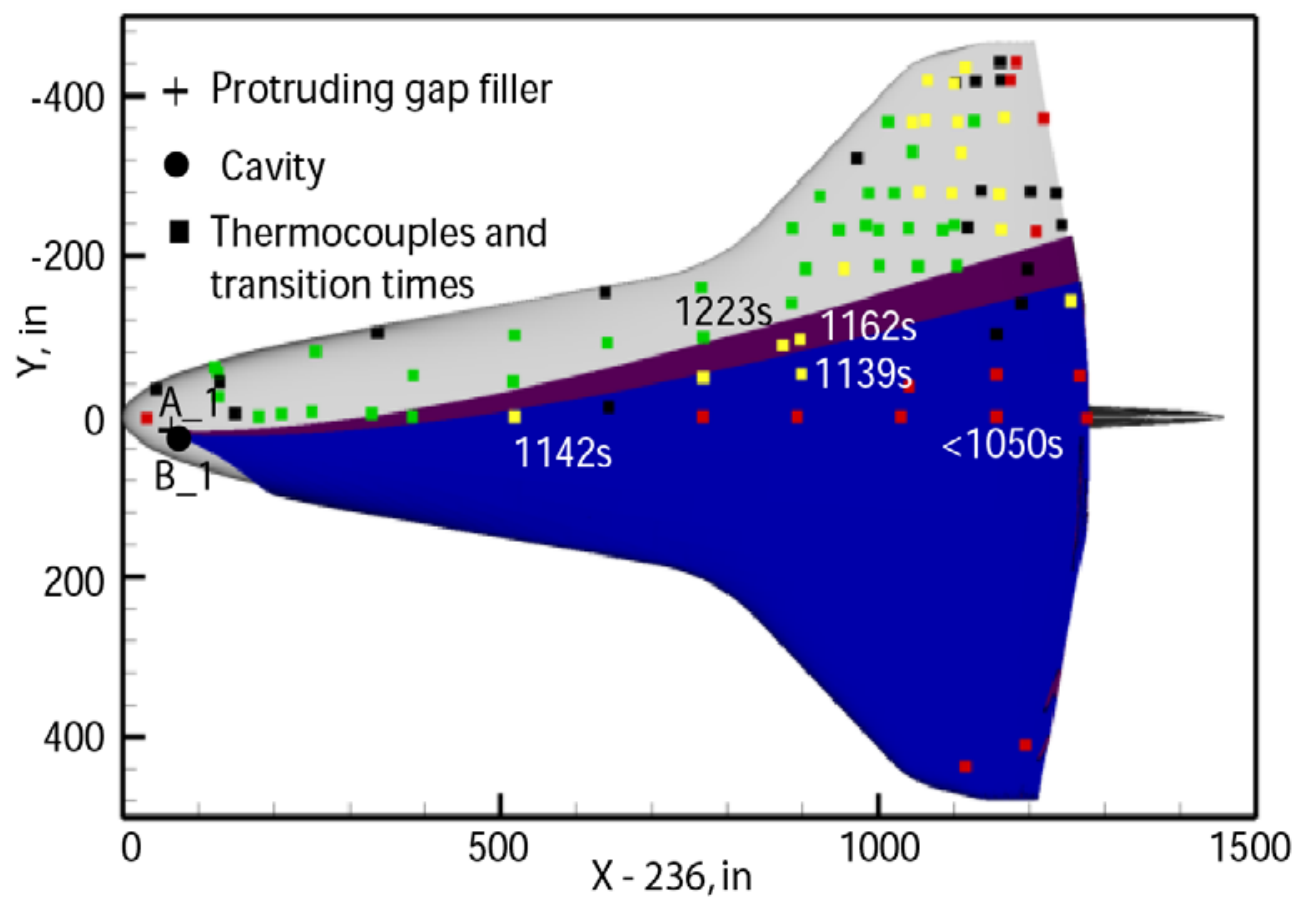

Figure 9. Early Boundary Layer Transition due to Debris Damage on STS-1 was caused by a large gouge on the starboard Nose Landing Gear Door and related, exposed gap filler.

The windward surface thermocouple locations are shown in red, if transition had already occurred before 1050 seconds, when the telemetry was acquired. Yellow sensors indicate transition between 1050s and 1200s, while green instruments indicate transition after 1200s.

The yellow colored instrument, on the centerline, indicates that transition occurred at 1142 seconds after Entry Interface. The data from this location is plotted in Figure 7 and labeled as "STS-1 Flight Data." The blue and magenta wedges indicate the extent of the turbulent boundary-layer spreading, based on the Wedge Tool as described in Reference 13. Note that the turbulent boundary-layer crosses the vehicle centerline just ahead of the 500 inch station with the majority of the Port side remaining laminar until after 1200 seconds. Based on the vehicle accelerometer data, the flight Mach number when early transition occurred on the starboard side was between 15.4 and 13.6. It should be noted that all (prime contractor and NASA) of the pre-flight boundary-layer transition estimates indicated early transition (before Mach 8) on the aft end of the vehicle, presumably due to the wind tunnel disturbances (acoustical noise) in the test data. The flight environment is much quieter than hypersonic wind tunnels resulting in nominal transition occurring around Mach 8 in flight. A good description of this effect, along with plots from the OFT flights can be found in Reference 12.

\section{J. STS-3 Windward Surface Flight Data}


The data from STS-3 is typical of one of the Orbiter Flight Test, when data was successfully recorded for the entire entry, and is shown for three locations along the windward centerline in Figure 10. The surface temperature profile from Entry Interface, $\mathrm{T}=0$, indicates laminar heating until the boundary-layer transitions to turbulent flow as indicated by the increase in surface temperature, shown by the arrow in the figure. Note that boundary-layer transition occurs after the vehicle has passed through peak heating and that the turbulent heating yields a surface temperature that is less than, or only slightly greater than the laminar value. Although, not labeled in this work, the surface temperature is well below the tile material 100 mission reuse limit. In general, boundary-layer transition begins on the aft end of the vehicle and sweeps forward very quickly. On the aft end of the vehicle, transition began about 300 seconds later than the pre-flight predictions, and then flashed forward and was consistent with the preflight predictions on the forward end of the vehicle between $\mathrm{X} / \mathrm{L}=0.1$ and $\mathrm{X} / \mathrm{L}=0.2$. Thus for the majority of the windward surface, the pre-flight boundary-layer transition predictions were conservative. Nominal boundary-layer transition occurs similar to the data from STS-3, unless damage to the tiles or protruding gap filler initiated it prematurely. 


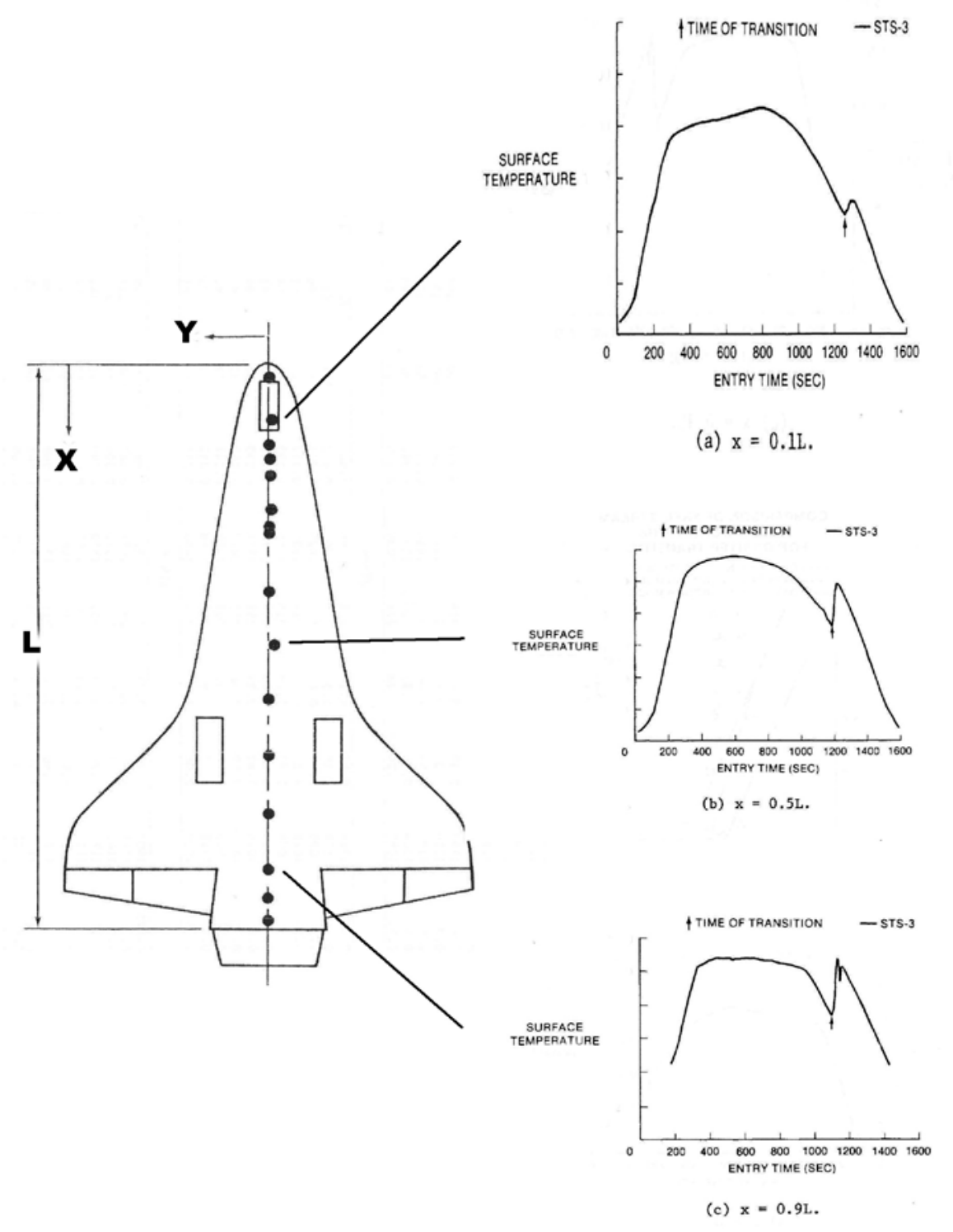

Figure 10. STS-3 Flight Surface Temperature vs. Time on the Vehicle Center-Line.

\section{K. Structural Thermal Response}

Since the tiles are extremely good insulators, only about $2 \%$ of the heat is conducted to the underlying structure, while the majority is radiated away by the high emissivity of the surface coating. A typical structural temperature response, from STS-1 is shown in Figure 11. While not labeled, it is well below the reuse limit of 450K (350F) for the aluminum structure. Note that the maximum occurs prior to landing. During entry, after the heating interval is over, the vehicle vent doors are opened to re-pressurize the vehicle, resulting in a significant reduction in temperature, relative to the pre-flight predictions. This cooling effect, which occurs at most, but not all locations, was not considered prior to STS-1, and is a significant source of margin where it applies. ${ }^{18}$ 


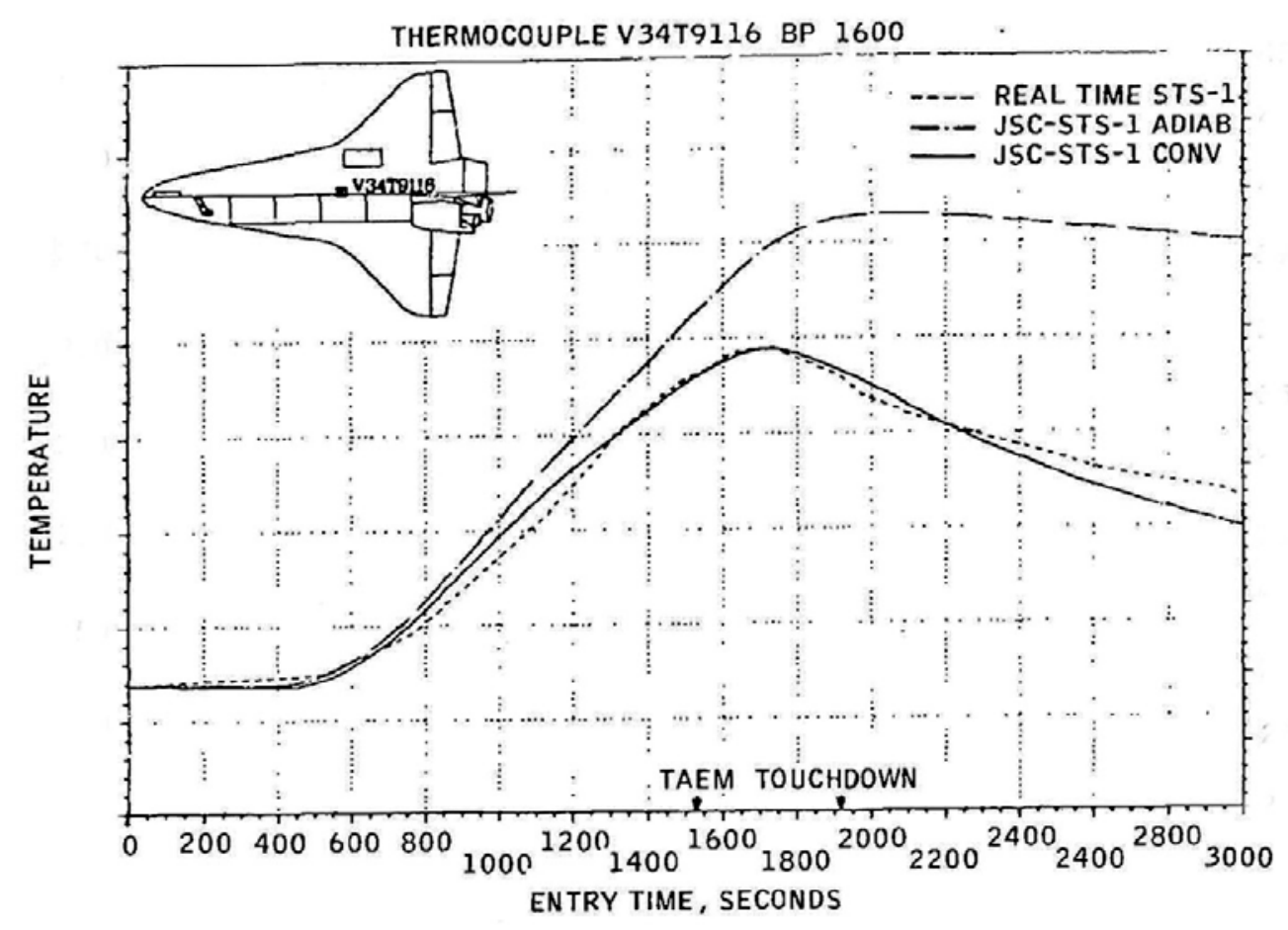

Figure 11. Typical structural temperature where convective cooling reduces the maximum temperature relative to the pre-flight predictions.

\section{Margin Estimate}

A review of the maximum structural temperature, for each flight, indicates considerable margin in the acreage tile portion of the TPS. The margin is due to the typical trajectory being slightly less severe than the design trajectory, the nearly non-catalytic nature of the tile RCG coating, conservatism in the design assumptions used for boundary layer transition, and the cooling effect that was not anticipated. The highest structural temperature was measured on STS-73 (STS-28 also had essentially the same measurement) which had a protruding gap filler that caused early boundary-layer transition on a large portion of the windward surface as described in Reference 13, and caused transition to occur early, between Mach 18.7 - 16.4. However, considerable margin existed for additional heat load as the structural temperatures were still well below the design value of $450 \mathrm{~K}$ ( $350 \mathrm{~F}$ ).

The worst tile damage occurred on STS-27 when over 600 tiles were damaged, with 298 of them experiencing damage sites larger than $2.54 \mathrm{~cm}$ ( $1 \mathrm{in}$ ). The maximum recorded structural temperature was slightly less than, but essentially the same as STS-73. The worst damage (STS-27) occurred near the nose and resulted in the softening, and flowing, of the tin plating on an aluminum antenna cover. The aluminum reached high enough temperatures to change the state of annealing, but the adjacent structure was not damaged due to conduction to the surrounding thermal mass.

\section{Boundary-Layer Transition Flight Experiment}

The need for additional research into early boundary-layer transition became obvious during the STS-114 mission when two protruding gap fillers were seen in the new TPS inspection images. ${ }^{19}$ Both gap fillers were outside of the experience base, due to their location on the forward end of the vehicle and their protrusion height. The assessment, during the mission, indicated that very early boundary-layer transition was likely, and the potential 
existed to exceed the wing leading edge, RCC panel 9, single mission temperature limit. Therefore, both of the gap fillers were removed during an EVA, making the first TPS repair by a crewman during a mission.

Following the mission, a flight experiment designed to improve the accuracy of the boundary-layer transition prediction methodology was proposed and ultimately flown five times with three different protuberance heights. STS- 119 flew a $6.35 \mathrm{~mm}$ (0.25 inch) protuberance, while later flights flew $8.89 \mathrm{~mm}$ ( $0.35 \mathrm{in})$ and $12.7 \mathrm{~mm}$ (0.5 in) protuberances. Figure 12 shows the $8.89 \mathrm{~mm}$ ( $0.35 \mathrm{in})$ protuberance tile after the STS-131 mission. The original plan was to fly the experiment on OV-103 only, however, the KSC teams recommended adding the DTO to OV-105 also, and thus additional data was obtained on the last flight of Endeavour during STS-134. The data from the Boundary-Layer Transition Detailed Test Objective (BLT DTO) confirmed that the existing methodology for predicting boundary-layer transition was accurate to 0.5 Mach number and thus was acceptable; however, the maximum predicted temperature was very conservative. The protuberance heating model was revised downward, based on the new flight data. The knowledge learned from the DTO was used to improve the Shuttle TPS damage assessment tools for the final missions and will be used in the design of future spacecraft.

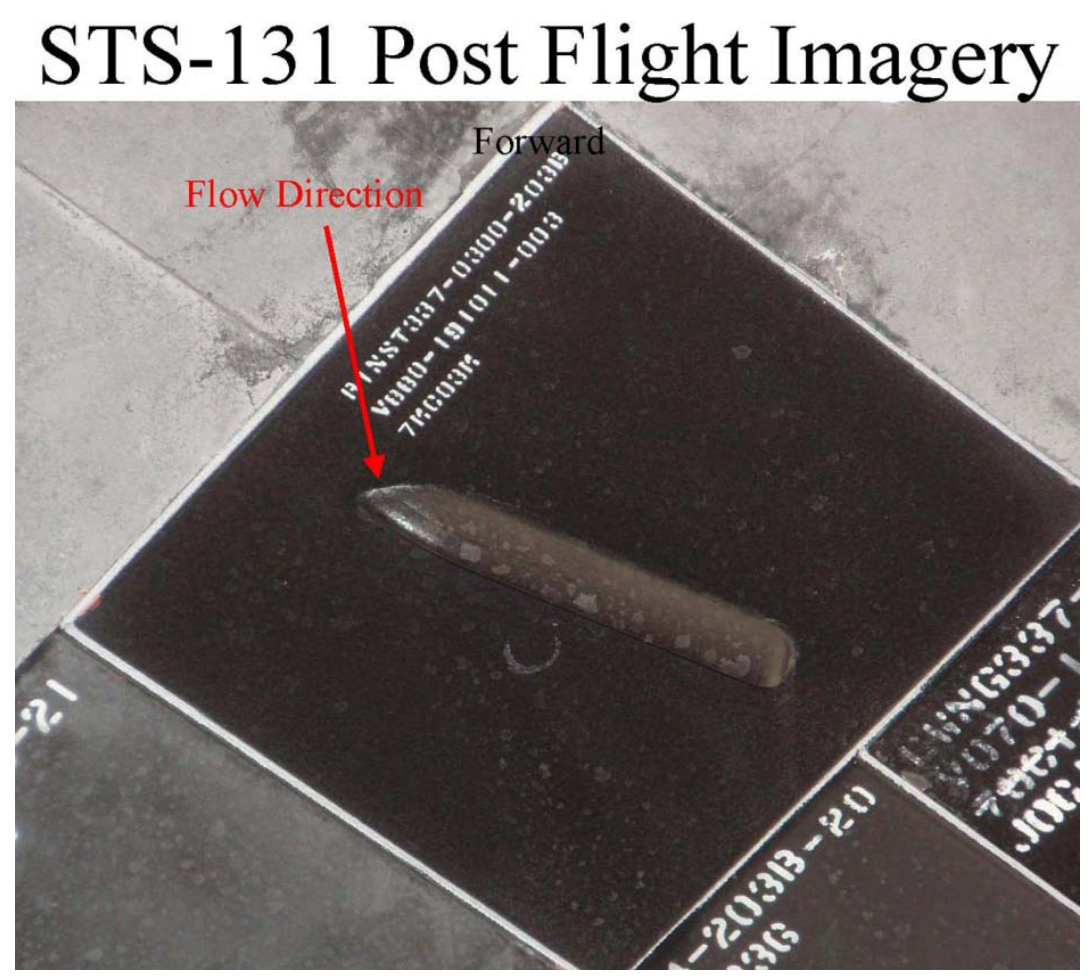

Figure 12. STS-131 post flight view of the BLT DTO tile.

\section{N. Orbiter TPS Tile Margin Summary}

The Orbiter windward surface tile system had significant margin, due to the conservatism in the boundary-layer transition data used to design the system, the convective cooling for much of the vehicle that was not anticipated during the design, and the non-catalytic nature of the tile coating. While not the factor of 2 that most of the Apollo heat shield had, it was enough to tolerate considerable damage during ascent, provided the underlying structure was not penetrated. And the pre-flight boundary-layer transition estimates, which are very conservative for a nominal mission, added additional margin for the flights when unexpected tile damage or protruding gap fillers occurred.

\section{O. Return-to-Flight TPS Assessment Team}

A team, dedicated to safely flying the remaining Shuttle missions, was assembled from the technical experts that had investigated the loss of Columbia. They ran additional hypersonic wind tunnel test, MH-13, to obtain high resolution wing leading edge heat flux data and to investigate boundary-layer transition characteristics. Extensive boundary-layer transition testing was carried out at NASA Langley Research Center. In addition, a significant 
number of arc jet tests were performed at both the NASA-Langley and JSC facilities to investigate cavity heating levels for representative tile damage scenarios. This information was used to develop analytical tools for evaluating damage to the TPS, and was used to provide real time support for all of the remaining missions. The engineering tools developed by the Orbiter reentry aerothermodynamic community provided engineering correlation based convective heating to damaged tile, catalytic heating to damaged tile, and boundary-layer transition predictions for protuberances and small cavities. ${ }^{20}$

Along with testing and engineering tool development, a significant number of real gas, (reacting chemistry) CFD calculations were performed using the LAURA ${ }^{21,22}$ and DPLR ${ }^{23}$ codes, developed at NASA Langley and NASA Ames, respectively. A solution database was created for an undamaged Orbiter that was used to extract relevant flow properties as inputs into engineering codes. The database solutions were also used as a starting point for detailed cavity heating and other damage assessments. Rapid generation techniques and scripts were developed that enabled the team to provide solutions in a number of hours. Any damage that occurred during ascent was evaluated during the mission before declaring the TPS ready for entry. ${ }^{24,25}$

\section{Direct Simulation Monte Carlo Rarefied Flow Analysis}

\section{A. DSMC Analysis Code}

The technical challenges of the Space Shuttle Program have motivated the development of analysis tools that can handle complex geometry and complex flow physics while taking advantage of the dramatic improvements in computing power that has evolved during the last 4 decades. An excellent example is the Direct Simulation Analysis Code (DAC) ${ }^{26}$, which was developed to analyze the Shuttle Reaction Control System (RCS) jet plume impingement to the International Space Station solar arrays as shown in Figure 13. As the Orbiter RCS plume expands, the density drops low enough that the flow is no longer a continuum and traditional CFD techniques are not applicable. DAC uses the Direct Simulation Monte Carlo (DSMC) method, developed by Dr. Bird, to analyze rarefied flows, and was specifically written to handle complex geometries and run efficiently on massively parallel supercomputers. The code has successfully solved many rarefied flow problems in support of the ISS development and assembly, Hubble repair missions, Shuttle/MIR missions, and support to the Mars Global Surveyor mission when one of its solar arrays did not deploy completely.

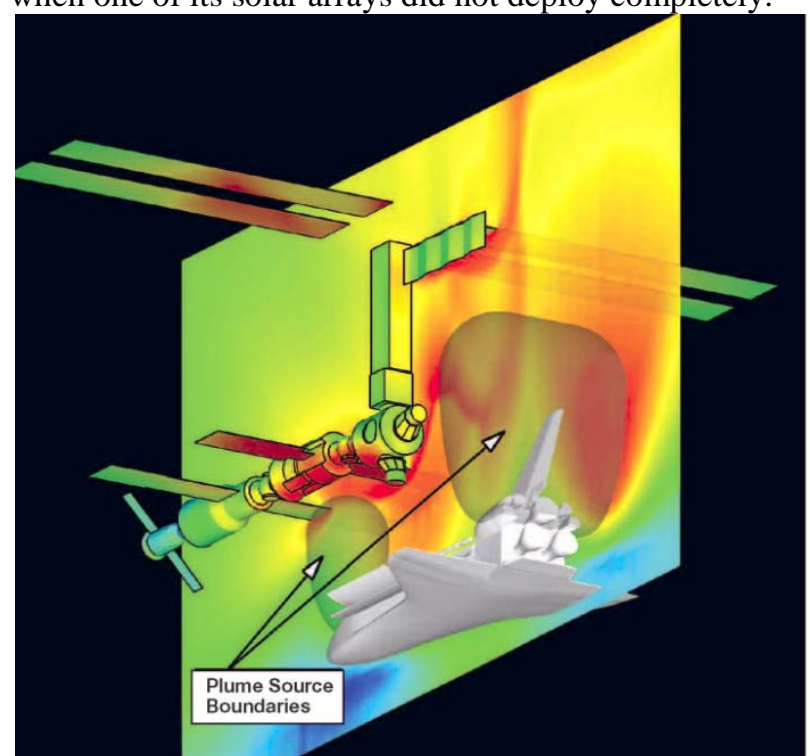

(a)

Figure 13. DAC predictions of the Orbiter RCS plume impingement to the (a) International Space Station and the (b) MIR Space Station.

\section{B. Space Shuttle Launch Vehicle Aerodynamic Issues}

Another outstanding example of the Shuttle Program motivating the development of tools is the work performed at the Ames Research Center by Dr. Joseph Steger's team in support of the Shuttle launch vehicle aerodynamic 
analysis. The pre-flight aerodynamic database was inadequate in the transonic Mach range due to plume and Reynolds number scaling limitations. ${ }^{27,28}$ The Chimera overlapping grid approach, combined with the development of the OVERFLOW CFD code, developed by Dr. Pieter Buning, was the first method that could accurately predict the ascent flow field at flight Reynolds Number with all five plumes. ${ }^{29,30,31,32,33,34}$ The resulting flow field is shown in Figure 14. The insight obtained into the very complex launch vehicle aerodynamic loads was an essential part of the Performance Enhancement Certification that made the launching of the ISS components possible. As shown in Figure 15, OVERFLOW also became an essential tool for the study of debris during launch ${ }^{3536}$, and was critical to the ET Bi-pod redesign after the loss of Columbia and the work that allowed the removal of the Protuberance Airload Ramp (PAL) foam after STS-114. ${ }^{37}$ An excellent overview of the launch vehicle CFD support during the last 20 years is provided in Reference [38].

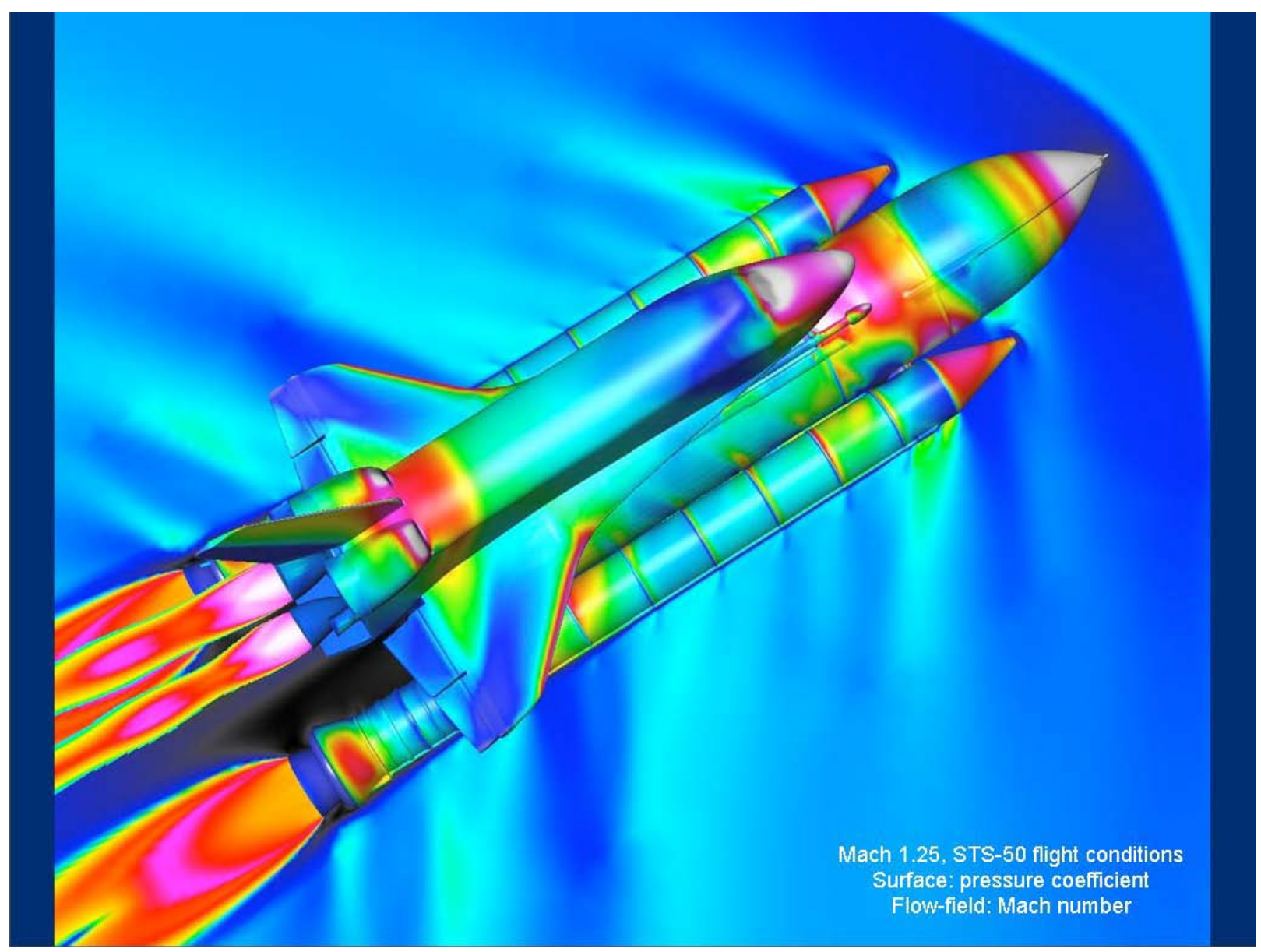

Figure 14. Space Shuttle Launch Vehicle flow field prediction at Mach 1.25.

OVERFLOW was also used to study the unsteady flow dynamics in the 17 inch feedline, which led to cracks forming in the feedline flow liners. The unsteady, separated flow at the low pressure turbo pump inlet was shown to act upstream in a manner that was causing high cycle fatigue cracks in the flow liner material. ${ }^{39}$ 


\section{After validation had been established CFD was a key part of many External Tank redesign assessments and debris assessments.}

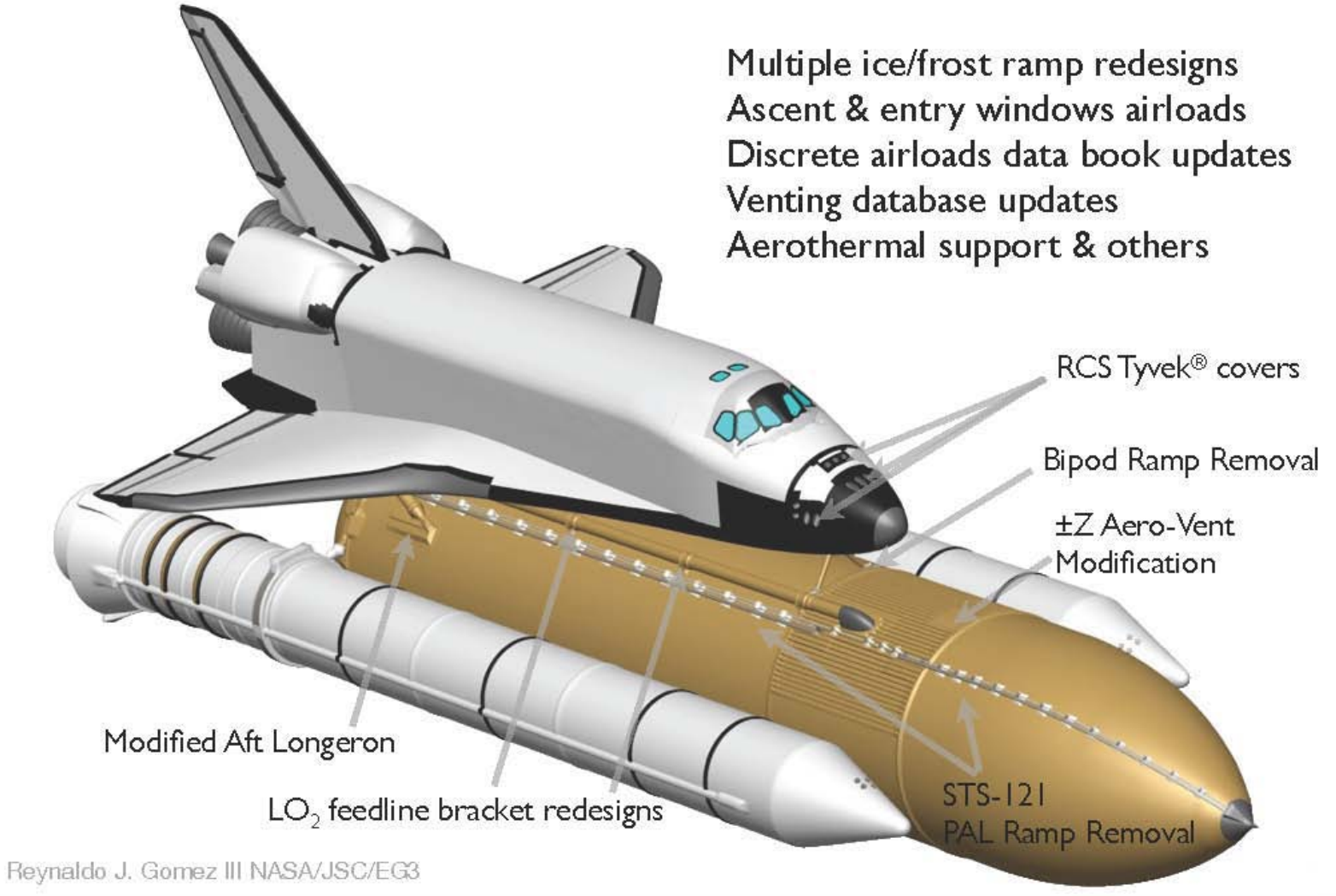

Figure 15. CFD predictions of the ascent aero loads and flow field were essential for many Space Shuttle improvements.

\section{Conclusions}

During the last 40 years, thousands of talented and dedicated personnel in industry, NASA, and academia have contributed to the design, construction, maintenance, and flight operations of an amazing winged spacecraft. While they cannot all be recognized in this short paper, their contributions were essential in preparing for the launch of STS-1 through the support of the last mission, STS-135. The experience gained during the last 30 years, along with the dramatic improvement in analysis capability provides the foundation for the development of the next generation of spacecraft. The flight data obtained during the life of the Program (primarily the OFT flights and the BLT DTO flights) is an invaluable resource that can and should be used to validate future analysis tools. Hopefully, the young members of the aerospace industry, who have already entered the discipline, will be using the Space Shuttle data to validate their numerical simulations of the boundary-layer transition process, without a turbulence model, during their careers.

Furthermore, the dramatic improvement in analysis tools, supplemented by empirical methods and flight data, for validation, provide a means of reducing uncertainty in the design process. However, a systems approach is still essential so that the uncertainty in each aspect of the design, (structures, thermal protection system, heating, etc.) isn’t compounded unnecessarily.

\section{Acknowledgments}

The author would like to thank Dr. Robert Ried, Ms. Dorothy Lee, and Mr. Stephen Derry for their helpful discussions concerning the development of the Space Shuttle aerothermodynamic environment and the Orbiter TPS 
design objectives. Also, Mr. Stan Bouslog was very helpful with his experience with the Orbiter asymmetric boundary-layer transition. Dr. Charles Campbell and Mr. Brian Anderson were very helpful in explaining their extensive experience with the Orbiter entry flight support, TPS damage assessment tools, and development of the BLT flight experiment. Also, Dr. Catherine McGinley graciously provided the pictures for Figures 8 and 9 from Reference 18. The DSMC results were provided by Mr. Gerald Lebeau, and the launch vehicle figures by Mr. Reynaldo Gomez.

\section{References}

\footnotetext{
${ }^{1}$ Ried, R. C.: “Orbiter Entry Aerothermodynamics,” NASA CP-2342, Part 2, pp. 1051-1061.

${ }^{2}$ Ried, R. C.; Goodrich, W. D.; Li, C. P.; Scott, C. D.; Derry, S. M.; Maraia, R. J.: "Space Shuttle Orbiter Entry Heating and TPS Response: STS-1 Predictions and Flight Data,” pp. 327-347.

3 Pavlosky, J. E.; St. Leger, L. G.: “Apollo Experience Report - Thermal Protection Subsystem,” NASA TN D7564, January, 1974.

${ }^{4}$ Lee, D. B., Harthun, M. H.: “Aerothermodynamic Entry Environment of the Space Shuttle Orbiter,” AIAA 820821
}

${ }^{5}$ Martindale, W. R., Trimmer, L. L., “Test Results from the NASA/Rockwell International Space Shuttle Test (OH4A) Conducted in the AEDC-VKF Tunnel B.,” AEDC-DR-74-39, may 1974.

${ }^{6}$ Haney, J. W.; Petrilla C. T.: Space Shuttle Orbiter Entry Aerodynamic Heating Data Book. Rockwell International Space Division, SD73-SH-0184C, Oct. 1978.

${ }^{7}$ Goodrich, W. D., Li, C. P., Houston, C. K., Chiu, P. B., and Olmeda, L.: "Numerical Computations of Orbiter Flow Fields and Laminar Heating Rate,” Journal of Spacecraft and Rockets, Vol 14, May 1977, pp. $257-264$.

${ }^{8}$ Rakitch, J. V. and Lanfranco, M. J.: "Numerical Computation of Space Shuttle Laminar Heating and Surface Streamlines,” Journal of Spacecraft and Rockets, Vol. 14, No. 5, May 1977, pp. 265-272.

${ }^{9}$ Van Driest, E. R., and Blumer, C. B., "Boundary-Layer Transition at Supersonic Speeds - Three Dimensional Roughness Effects (Spheres),” Journal of the Aerospace Sciences, Aug. 1962, Vol. 29, No. 8, pp. 909-926.

${ }^{10}$ Goodrich, W. D., Stalmach, C. J. Jr., "Effects of Scaled Heatshield Tile Misalignment on Orbiter Boundary-Layer Transition”, Journal of Spacecraft and Rockets, Vol 14, No. 10, October 1977, pp. 638

${ }^{11}$ Goodrich, W. D., Derry, S. M., Bertin, J. J., "Shuttle Orbiter Boundary-Layer Transition: A Comparison of Flight and Wind Tunnel Data,” AIAA-83-0485

12 Scott, C. D., “A Review of Nonequilibrium Effects And Surface Catalysis On Shuttle Heating,” NASA CP-2283, Part 2, pp. 865

${ }^{13}$ Rakich, J. V., Stewart, D. A., Lanfranco, M. J., "Results of a Flight Experiment on the Catalytic Efficiency of the Space Shuttle Heat Shield,” AIAA-1982-944, June 1982.

14 Stewart, D. A., Rakich, J. V., and Lanfranco, M. J., "Catalytic Surface Effects of Space Shuttle Thermal Protection System During Earth Entry of Flights STS-2 Through STS-5,” Paper presented at Langley Conference on Shuttle Performance: Lessons Learned, Hampton, Va., March 1983.

${ }^{15}$ Rakich, J. V., Stewart, D. A., and Lanfranco, M. J., "Results of a Flight Environment on the Catalytic Efficiency of the Space Shuttle Heat Shield,” AIAA Paper 82-0944, June 1982.

${ }^{16}$ Marichalar, J. J., Rochelle, W. C., Kirk, B. S., Campbell, C. H., "BLIMPK/Streamline Surface Catalytic Heating Predictions on the Space Shuttle Orbiter,” AIAA 2006-180, January 2006.

${ }^{17}$ McGinley, C. B., Berry, S. A., Kinder, G. R., Barnwell, M., Wang, K. C. and Kirk, B. S., "Review of Orbiter Flight Boundary Layer Transition Data,” AIAA-2006-2921

${ }^{18}$ Dotts, R. L., Curry, D. M., Tillian, D. J., “Orbiter Thermal Protection System,” NASA-CP-2342, Part 2, pp. 1062 $-1081$

${ }^{19}$ Berry, S. A., Horvath, T. J., Cassady, A. M., Kirk, B. S., Wang, K. C., Hyatt, A. J., “Boundary Layer Transition Results from STS-114,” AIAA 2006-2922, June 2006.

${ }^{20}$ Hyatt, A. J., Wang, K. C., Everhart, J. L., Green, F., Merski, N. R., Wood, W. A., Berger, K., Anderson, B. P., Cassady, A., “The Cavity Heating Tool: Version 3.0 Documentation,” Bowing Technical Memorandum, ATA-AHTM-2006-035, Houston, TX, 2006.

${ }^{21}$ Gnoffo, P. A., Gupta, R. N., and Shinn, J. L., "Conservation Equations and Physical Models for Hypersonic Air Flows in Thermal and Chemical Nonequilibrium,” NASA TP 2867, Feb. 1989.

${ }^{22}$ Gnoffo, P. A., “An Upwind-Biased, Point-Implicit Relaxation Algorithm for Viscous, Compressible Perfect-Gas Flows,” NASA TP 2953, Feb. 1990. 
${ }^{23}$ Tang, C., Saunders, D., Trumble, K., Driver, D., "Rapid Aerothermal Simulations of Damage and Repair During a Space Shuttle Mission,” AIAA 2007-1783, April 2007.

${ }^{24}$ Campbell, C. H., et. Al., “Orbiter Return to Flight Aeroheating,” AIAA 2006-2917

${ }^{25}$ Palmer, G. E., et. Al., "Computational Assessment of Thermal Protection System Damage Experienced During STS-118,” Journal of Spacecraft and Rockets, 2009, vol. 46, no. 6

${ }^{26}$ LeBeau, G. J. and Lumpkin, F. E., "Application Highlights of the DSMC Code (DAC) Software for Simulating Rarefied Flows," Computer Methods in Applied Mechanics and Engineering, Vol. 191, Issue 6-7, (2001) 595-609.

${ }^{27}$ Surber, T. E., and Stone, J. S., "Aerodynamic Analysis of the Loft Anomaly Observed on Orbital Flight Test of the Space Shuttle,” NASA CP-2283, pages 59-77.

${ }^{28}$ Hamilton, J. T., Wallace, R. O., and Dill, C. C., "Launch Vehicle Aerodynamic Data Base Development Comparison With Flight Data," NASA CP-2283, pages 19-36.

${ }^{29}$ Buning, P. G., Chiu, I. T., Obayashi, S., Rizk, Y. M., and Steger, J. L., "Numerical Simulation of the Integrated Space Shuttle Vehicle in Ascent,” AIAA-88-4359-CP, August 1988.

${ }^{30}$ Pearce, D. G., et Al., "Development of a Large Scale Chimera Grid System for the Space Shuttle Launch Vehicle,” AIAA-93-0533, January 1993.

${ }^{31}$ Martin, F. W, Jr., Labbe, S. G., Wey, T. C. and Pearce, D. G., "Space Shuttle Launch Vehicle Wind Tunnel and Flight Aerodynamic Environments,” AIAA-94-1861.

${ }^{32}$ Slotnick, J. P., Kandula, M., and Buning, P. G., "Navier-Stokes Simulation of the Space Shuttle Launch Vehicle Flight Transonic Flow Field Using a Large Scale Chimera Grid System,” AIAA-94-1860, June 1994.

${ }^{33}$ Slotnick, J. P., Kandula, M., Buning, P. G. and Martin, F. W., Jr., "Numerical Simulation of the Space Shuttle Launch Vehicle Flowfield with Real Gas Solid Rocket Motor Plume Effects,” AIAA-93-0521, January, 1993.

${ }^{34}$ Gomez, R. J., and Ma, E. C., "Validation of a Large Scale Chimera Grid System for the Space Shuttle Launch Vehicle,” AIAA-94-1859

${ }^{35}$ Huyse L., Waldhart, C., Riha, D., Thacker, B., Larsen, C., Gomez, R. and Stuart, P., "Probabilistic Modeling of Space Shuttle Debris Impact," AIAA-2007-1954.

${ }^{36}$ Boyles, K. A., "Debris Transport Analysis for Space Shuttle Forward RCS Tyvek Rain Covers Based on 2006 Delta-Certification,” JSC-63498, June 2006.

${ }^{37}$ Panda, J. and Martin, F., "Estimation of the Unsteady Aerodynamic Load on Space Shuttle External Tank Protuberances from a Component Wind Tunnel Test," AIAA-2008-232.

${ }^{38}$ Gomez, R. J., "20+ Years of Computational Fluid Dynamics for the Space Shuttle,” High Performance Computing User Forum meeting, April 2011.

${ }^{39}$ Kiris, C., Kwak, D., Chan, W. and Housman, J., "High Fidelity Simulations of Unsteady Turbopumps and Flowliners,” AIAA-2006-89, January 2006. 